
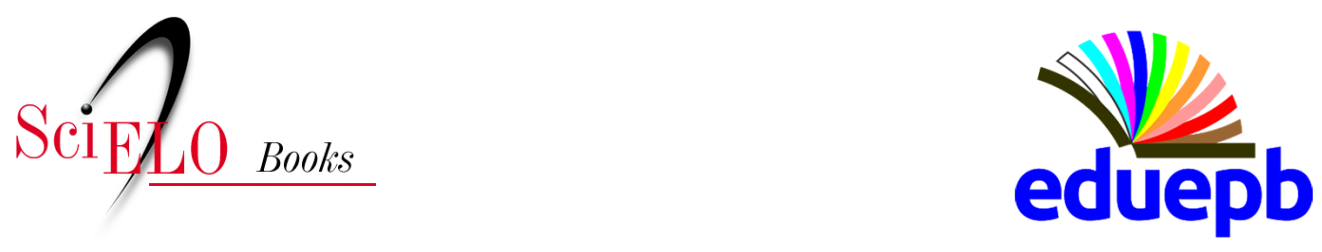

\title{
Influências e Legados \\ Leonides Alves da Silva Filho - O Nordeste e um instrumento de desenvolvimento regional
}

João Morais de Sousa

\section{SciELO Books / SciELO Livros / SciELO Libros}

SOUSA, J. M. Leonides Alves da Silva Filho - O Nordeste e um instrumento de desenvolvimento regional. Interviewed: Leonides Alves da Silva Filho. In: SOUSA, C. M., THEIS, I. M., and BARBOSA, J. L. A., eds. Celso Furtado: a esperança militante (Depoimentos): vol. 2 [online]. Campina Grande:

EDUEPB, 2020, pp. 201-223. Projeto editorial 100 anos de Celso Furtado collection. ISBN: 978-65-86221-11-4.

https://doi.org/10.7476/9786586221671.0008.

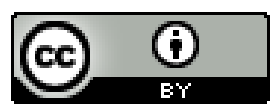

All the contents of this work, except where otherwise noted, is licensed under a Creative Commons Attribution 4.0 International license.

Todo o conteúdo deste trabalho, exceto quando houver ressalva, é publicado sob a licença Creative Commons Atribição 4.0.

Todo el contenido de esta obra, excepto donde se indique lo contrario, está bajo licencia de la licencia Creative Commons Reconocimento 4.0. 


\section{Leonides Alves da Silva Filho*}

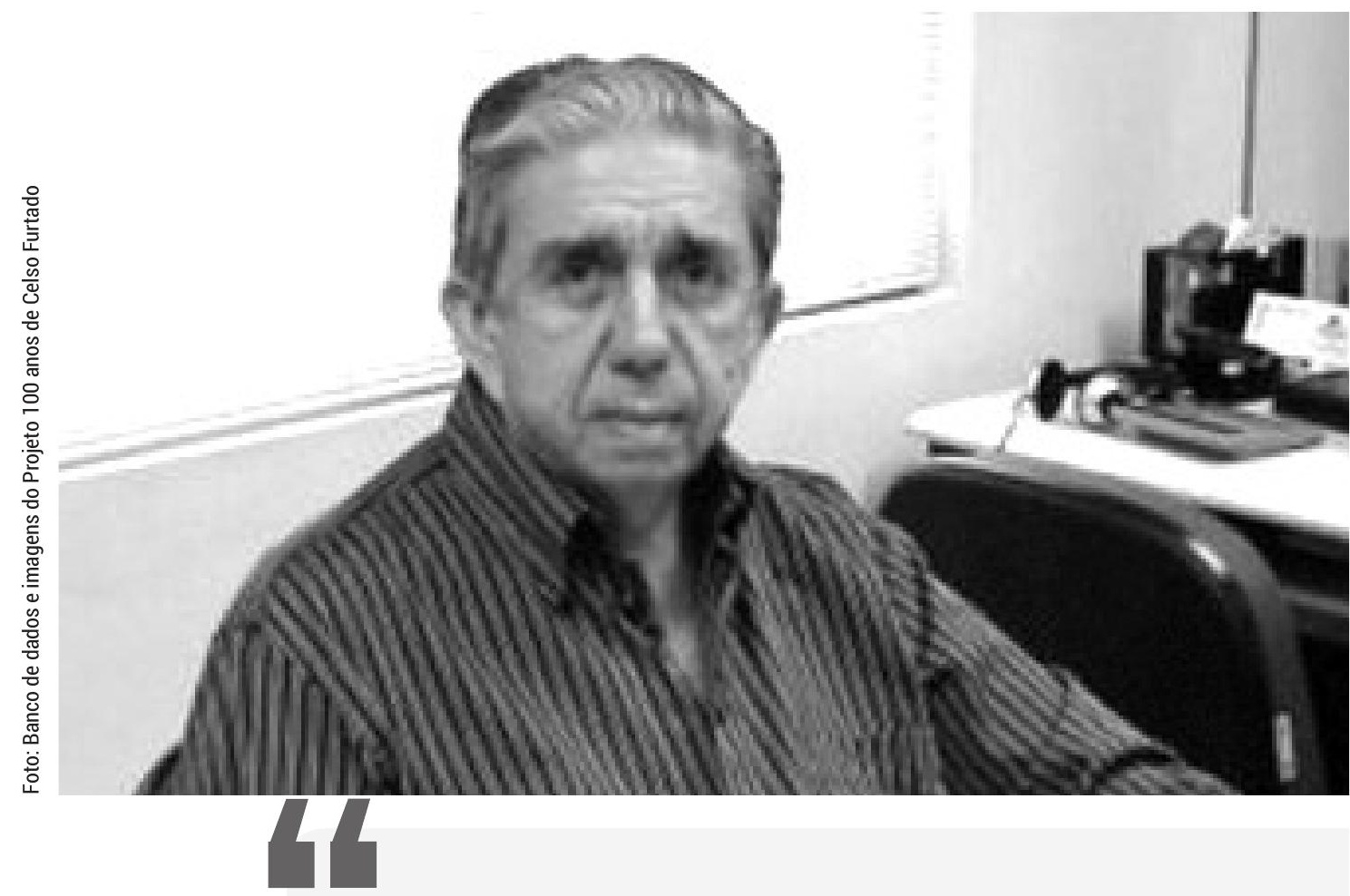

A Sudene foi uma instituição que ordenou o processo e criou na região um tratamento de desenvolvimento para os problemas do Nordeste. Anteriormente, o único tratamento que tinha de enfoque de política era o aumento da oferta d'água, que era o grande papel do DNOCS. A Sudene contribuiu para gerar uma mentalidade, um tratamento e uma abordagem global em termos de desenvolvimento dos problemas da região. Todo enfoque era dar um tratamento global e evitar o pires na mão, a nível do governo central.

* Entrevista realizada em 14/12/2014, no contexto das atividades do Procondel (Sudene - UFPE), por Angela Nascimento, mestre em Ciência da Informação, e Fernando Weller, cineasta, doutor em Comunicação pela UFPE, professor e Coordenador adjunto do Departamento de Comunicação da mesma universidade, e cedida aos organizadores da Trilogia Celso Furtado: a esperança militante. 


\section{O Nordeste e um instrumento de desenvolvimento regional}

$\mathrm{O}$ piauiense Leonides Alves da Silva Filho é bacharel em administração pela Escola Brasileira de Administração Pública da Fundação Getúlio Vargas (EBAP/FVG) e bacharel em direito pela Universidade Federal de Pernambuco (UFPE). É professor aposentado da UFPE. Integrou os quadros técnicos da Sudene por mais de 30 anos e durante este período ocupou diversas comissões, diretorias, foi Superintendente de Desenvolvimento Social, de Infraestrutura e Superintendente Adjunto. Também chegou a ser consultor das Nações Unidas (em Caracas e em Lima) e da Vice-Presidência da República.

No início da fundação da Sudene compôs seu Conselho Deliberativo como Secretário de Planejamento do Estado do Piauí, período que passou a conviver com Celso Furtado e a ser influenciado pelo intelectual paraibano na sua forma de pensar e de atuar sobre o planejamento e sobre a questão do desenvolvimento do Nordeste.

Durante a sua trajetória profissional o professor Leonides organizou, coordenou, apresentou e publicou diversos trabalhos técnicos e científicos em eventos (congressos, simpósios, colóquios, seminários) nacionais e internacionais, sempre envolvendo as temáticas do planejamento, do desenvolvimento do Nordeste e do papel da Sudene nesses processos. Destaques para os livros: "Sudene 50 anos: uma abordagem política, institucional e administrativa" (2009) e "Piauí: uma política de desenvolvimento" (2010). Também foi Coordenador do Movimento Acorda Nordeste (MANO) e Presidente do Instituto Nacional de Administração para o Desenvolvimento (INAD), com sede em Recife.

Em reconhecimento a longa e profícua carreira pública, o professor Leonides recebeu várias homenagens, inclusive da Câmara Federal em 2016, pela passagem dos seus 80 anos, em razão da sua caminhada pública na Sudene e a pela sua atuação em pró do desenvolvimento do Nordeste. Recebeu, também, a Medalha do Mérito Joaquim Amazonas (2019), concedida pela Ordem dos Advogados do Brasil - Seccional Pernambuco. 
A entrevista com o professor Leonides Alves foi realizada pelos pesquisadores Angela Nascimento e Fernando Weller, no contexto do Projeto Procondel (Sudene/UFPE)'. Começou com ele discorrendo sobre o seu percurso de formação, sua chegada e trajetória na Sudene. Afirmou que é produto da instituição, mesmo considerando que passou 35 anos como professor da UFPE - ensinando disciplinas de "administração para o desenvolvimento". Disse que participou da Fundação da Sudene, integrando seu primeiro Conselho Deliberativo e que, a partir daquele momento, passou a ter muito contato com o pessoal de vanguarda, como Celso Furtado e Naílton Santos. Terminada a gestão na Secretaria de Planejamento do Estado do Piauí, fez concurso e ingressou nos quadros técnicos da Sudene.

Para o professor Leonides, a criação da Sudene não foi uma vontade pessoal do presidente Juscelino Kubitschek: ele foi pressionado a criá-la em função das secas simultâneas, do contexto internacional e, sobretudo, das tensões sociais na região, destacando-se, nesse contexto, as Ligas Camponesas, comandadas por Francisco Julião, e a influência da Igreja Católica. Segundo ele, as tensões, "dentro de uma postura esquerdista”, também deixaram as elites dominantes receosas e temendo a quebra da estabilidade política e o não atendimento de seus interesses.

De acordo com Leonides, os primeiros movimentos de desenvolvimento no Nordeste se deram com a criação do DNOCS, a instalação da Chesf, a criação do BNDE (hoje BNDES) e a criação do Banco do Nordeste e, depois, a Sudene. Nessa perspectiva, explicitou que o desenvolvimento passou a ser entendido como o aumento do produto interno bruto, geração de emprego e renda "em decorrência da combinação dos fatores de produção”. Historiciza o processo sociopolítico da criação da Sudene e a vinculação de Celso Furtado com esse contexto e, também, com a política de desenvolvimento do Nordeste. Aponta que a grande contribuição de Celso Furtado foi trazer a mudança do entendimento sobre desenvolvimento que até então era visto, pela maioria dos profissionais da região, só pelo viés econômico.

1 O Procondel (http://procondel.sudene.gov.br/) foi o projeto de preservação e disponibilização do acervo do Conselho Deliberativo da Sudene Condel, período 1959 200o, realizado pela Sudene em parceria com a Universidade Federal de Pernambuco entre 2013 e 2016, e tinha como meta a preservação desse acervo e a universalização do seu acesso, coordenado pelo professor doutor Marcos Costa Lima e pela professora mestra Angela Nascimento. 
Afirmou, ainda, que Celso Furtado trouxe para a Sudene muito da filosofia e da ação da CEPAL e acrescentou que a sua capacidade de negociação e articulação transformou o que era predominantemente planificação estatal, em uma ação planificadora global, envolvendo a integração entre o setor público e o setor privado. Na leitura de Leonides, Furtado incutiu essas ideias no corpo técnico da Sudene (o desenvolvimentismo), mas tudo isso acabou profundamente comprometido com o golpe de 1964 .

Indagado se a Sudene era um projeto avançado demais para a sociedade na época, respondeu que "era extremamente avançado e que continua sendo". Concluiu afirmando que o papel da Sudene no desenvolvimento do Nordeste foi de "contribuir para gerar uma mentalidade, e um tratamento, e uma abordagem global em termos de desenvolvimento dos problemas da região".

(João Morais de Sousa) ${ }^{2}$

\section{Entrevista}

- A gente queria começar assim: o senhor contando a sua história, a sua formação, como o senhor chegou à Sudene, como foi a sua longa caminhada, para começar.

Muito bem, inicialmente eu agradeço a oportunidade de estar aqui para conversar sobre o que para mim é extremamente gratificante: a Sudene. Eu sou produto daquela instituição, embora eu tenha também trabalhado na universidade (UFPE) como professor de administração para o desenvolvimento durante 35 anos. Eu sou da Sudene e da universidade. Já que você me pediu para dizer alguma coisa, vamos lá. Depois de ter terminado o curso de Administração na Fundação Getúlio Vargas, no Rio de Janeiro, eu fui para o estado do Piauí. Eu sou de lá. E lá nós criamos a Secretaria de Planejamento. Fui secretário da Fazenda, de Administração, do Planejamento. Tinha,

2 Sociólogo, doutor em Sociologia e Professor Associado do Departamento de Ciências Sociais da UFRPE. Publicou livros e artigos sobre coronelismo, poder local, ensino de ciências sociais, o universo da seca, turismo e educação. Estuda, atualmente, as relações entre arte, cultura popular, cidadania e desenvolvimento sustentável 
por consequência, muito relacionamento com a Sudene. Porque na condição de Secretário de Planejamento eu era o representante do Estado no Conselho Deliberativo. Todo mês eu vinha aqui, tinha muito contato, o tempo todo, com Celso Furtado, com os outros diretores antigos, altamente competentes, como Naílton Santos, Juarez Farias, Marcos Lins... Todo esse pessoal de vanguarda. Mas [eu vinha] na condição de conselheiro, defensor dos interesses do estado do Piauí.

- Então, doutor Leonides, nesse momento o senhor era do Conselho, mas como e quando o senhor passou para o outro lado do campo, por exemplo?

Quando houve a mudança política do governador, que eu trabalhava para o governador vencedor, que embora fosse meu amigo também, o famoso político nacional Petrônio Portella Nunes, eu resolvi fazer uma experiência de desenvolvimento global e escolhi a Sudene. A Sudene estava em concurso, em duas etapas. Na etapa I, nós tínhamos que apresentar um trabalho para julgamento, e eu apresentei um trabalho sobre desenvolvimento agrário no Nordeste. Passando na primeira etapa, eu então fiz a segunda e também fui aprovado, mas a gente só era admitido se fizesse um curso de técnico em desenvolvimento, de seis meses. Era a condição final para admissão. E aí eu cheguei à Sudene, inicialmente, como técnico. Mas nessa conversa eu gostaria de enfatizar os aspectos políticos institucionais e administrativos da instituição e tentar tirar algumas lições, já que é um depoimento com ênfase histórica. O primeiro aspecto que eu gostaria de ressaltar é que a Sudene não surgiu por uma mera vontade do presidente Juscelino Kubitschek. O presidente foi induzido a criar uma instituição de desenvolvimento regional para o nordeste. Por quê? Na década de 1950, havia uma fermentação social no Nordeste, incontrolável. Nós tínhamos aqui, comandados por Francisco Julião, as Ligas Camponesas, que faziam uma grande mobilização social. As tensões sociais aumentavam, secas periódicas assolavam a região, a Igreja se movimentou no sentido de tentar forçar uma tensão maior do governo federal para o Nordeste, e, ao lado disso, havia uma fermentação nacional e internacional no sentido de começar a tratar os problemas sob o enfoque do desenvolvimento. Desenvolvimento entendido como aumento do produto interno bruto, e, simultaneamente, geração de emprego e renda em decorrência da combinação 
dos fatores de produção. Então vejam: o primeiro sinal de instituição de desenvolvimento do Nordeste foi a criação da Chesf por Getúlio Vargas, em 1945, e que foi instalada em 1948, tendo como sede o Rio de Janeiro. O primeiro presidente da Chesf foi Apolônio Sales. A Chesf, em 1954, lançou a primeira grande usina: inaugurou Paulo Afonso, com 18o MW. O governo foi muito criticado, na época, porque achava que tinha feito um investimento de mais para consumo de menos. Em seguida, no plano internacional, foi criada a Cepal, a Comissão Econômica para a América Latina, em 1948. E aí se iniciou todo um processo de tratamento dos problemas econômicos dentro de um enfoque de desenvolvimento. A Cepal tinha uma abordagem do processo que na época se chamava planificação do desenvolvimento. A ação planificadora era centrada basicamente na intervenção do Estado; não era na atividade privada. Mas as tecnologias se desenvolveram enormemente. No Brasil, em junho de 1952, foi criado o Banco Nacional de Desenvolvimento Econômico (na época, BNDE), que surgiu como uma grande instituição de desenvolvimento. Um mês depois, em julho de 1952, foi criado o Banco do Nordeste do Brasil, a primeira instituição de desenvolvimento regional. Já havia o DNOCS, mas [atuando] dentro do enfoque de aumento da oferta da água, sem uma preocupação de desenvolvimento. Ao lado dessas duas instituições, secas simultâneas aconteciam na região e as Ligas Camponesas cresciam rapidamente dentro de uma postura esquerdista, que era moda, e que hoje já não é mais. Então, as elites dirigentes começaram a ter receio do que estava acontecendo porque o não atendimento de certas pretensões socioeconômicas da região poderiam pôr em risco a estabilidade política nacional, já que nós tínhamos e temos, de certa forma, 1/3 da população brasileira. Aí, aparece a Igreja católica. Os bispos promoveram uma reunião em Campina Grande, em 1956, e saiu uma carta registrando os principais fatos, exigindo uma posição do governo. Como decorrência da reunião de Campina Grande, também foi criado o Grupo de Trabalho para o Desenvolvimento do Nordeste - o GTDN. E quem foi presidir esse grupo foi um grande paraibano chamado Aluízio Campos. Nesse tempo, 1956, Celso Furtado não estava no Brasil. Ele era secretário geral da Comissão Econômica para a América Latina no Chile. O presidente do BNDES era o Cleantho de Paiva Leite. Esse pessoal todo eu convivi com eles. Cleantho, então, convidou Celso para vir para o Brasil assumir uma diretoria do BNDE. Celso Furtado deixou a Cepal e admitiu vir para o BNDE numa 
condição: de que na diretoria do banco ele tratasse, prioritariamente, dos problemas do Nordeste. Surgiu, aí, a vinculação de Celso com a política de desenvolvimento do Nordeste. Rapidamente, ele despontou lá da parte técnica e assumiu o GTDN. Desde então, passou a receber diretamente do presidente Juscelino Kubistchek determinações para tratar e encaminhar estudos do Nordeste. O quadro do Nordeste piorava assustadoramente. Em 1958, por iniciativa do deputado pernambucano, olindense, Barreto Guimarães³, juntamente com a Igreja, houve a reunião dos bispos em Salgueiro, reunião muito agitada. Tem documentação sobre isso. $\mathrm{E}$ a partir dessa reunião... ${ }^{4}$

\section{- Agitada por quê?}

Extremamente agitada dentro de um contexto de tensão, de exigências, de demonstração de que a instabilidade socioeconômica da região estava incontrolável. Logo em seguida, teve uma seca enorme também em 1958. Em janeiro de 1959, para não entrar em muitos detalhes históricos, o presidente Juscelino convocou uma reunião, que foi realizada no Palácio Rio Negro, em Petrópolis. Convocou governadores, políticos, [e] fez uma análise inicial de todo o quadro. Precisava tomar medidas urgentes, e convocou Celso Furtado. Celso fez uma exposição e apresentou as primeiras conclusões do GTDN. O presidente Juscelino determinou rapidez nos estudos e a apresentação de uma política para o desenvolvimento do nordeste o quanto antes. Acontece que a pressão sobre o presidente passou a ser extremamente forte. Em fevereiro do mesmo ano, ele convocou uma segunda reunião e, desta vez, no Palácio do Catete, no Rio de Janeiro. Para essa reunião ele convocou, inclusive, um membro da Igreja, o querido Dom Helder Câmara; convocou também os governadores, ministros, deputados, senadores. E nessa reunião, com base em sugestões do Celso Furtado, ele lançou a Operação Nordeste, conhecida como Openo. Era uma operação, não era um instrumento

3 José Antonio Barreto Guimarães (1923-1997) foi deputado estadual em Pernambuco, Vice-governador, secretário de Estado, prefeito de Olinda e Conselheiro do Tribunal de Contas Estadual.

$4 \mathrm{Na}$ realidade, o Encontro de Salgueiro foi realizado pela Comissão da Área da Secas da Assembléia Legislativa de Pernambuco, sob o comando do Deputado Barreto Guimarães. Vide artigo http://procondel.sudene.gov.br/ArtigosDetalhes.aspx?Id=1003. Já o Encontro dos Bispos aconteceu, o primeiro, em Campina Grande-PB, de 21 a 26 de maio de 1956; e o segundo, de 24 a 26 de maio de 1959, em Natal-RN. 
operativo para a promoção do desenvolvimento. Simultaneamente, ele criou o Conselho de Desenvolvimento do Nordeste - Codeno5, e designou Celso como secretário executivo. Qual é a primeira lição que eu gostaria de destacar para efeito de análise para pesquisadores e estudiosos? É que o Nordeste conquistou um instrumento de desenvolvimento regional. Não foi uma dádiva política. Graças a tensão social e a fermentação que estava havendo naquela quadra, o governo foi induzido a partir para a criação de uma instituição, numa tentativa de acalmar a região e evitar problemas maiores. Mesmo porque, na época, o governo era extremamente criticado. Ele estava no auge da construção de Brasília, de centralização das ações governamentais prioritariamente em Brasília, o que era verdade. E, simultaneamente, ele estava concentrando políticas especiais em São Paulo, principalmente na instalação da indústria automobilística, que surgiu também por essa época. De forma que aí o Nordeste conquistou esse espaço, criando a Sudene.

- Doutor Leonides, então essas coisas aconteceram: encontro dos bispos, encontro em Salgueiro, Codeno, Openo, o Decreto para criar a Sudene. O senhor estava onde, se formando no Rio? Como é que a juventude estava vendo isso, percebia essa movimentação?

Angela, na época eu comecei o curso de administração no Rio em 1956 e terminei em 1959. O nosso paraninfo, por coincidência, foi Celso Furtado, que eu não o conhecia. Acontece que eu sempre me interessei por esses aspectos. Eu fui do segundo curso de administradores formados no Brasil. Não havia isso no Brasil. Havia o técnico em administração do DASP, do Departamento Administrativo do Serviço Público. Então, eu comecei na Fundação e sempre me interessei bastante por esses aspectos econômicos. Existia no Brasil uma instituição considerada de esquerda chamada ISEB - Instituto Superior de Estudos Brasileiros, com grandes nomes nacionais: Cândido Mendes, Nelson Werneck Sodré, um sociólogo famoso internacional chamado Guerrero Ramos. Havia lá no ISEB um jornal chamado Semanário. Para a minha sorte, eu fui aluno do Guerrero Ramos, do

5 O Conselho de Desenvolvimento do Nordeste - Codeno foi instalado em 25 de abril de 1959, no Teatro Santa Isabel, no Recife-PE, com a presença do Presidente Juscelino Kubitschek. 
Aurélio Buarque de Holanda, autor do dicionário. Eles eram professores da Fundação Getúlio Vargas. Numa das aulas o Guerrero disse: "meu filho, você tem vocação de jornalista. Nós temos lá um jornal que está meio abandonado". Eu digo: "eu não entendo disso professor". "Não, mas não tem esse negócio de entender, não. O jornal é do Instituto. Tem um jornalista tal que orienta. Eu estou precisando de alguns alunos que no jornalismo a gente chama foca”. Então eu fui para o Semanário, e ali eu aprendi. Na época pesada do país, na época mais militarizada, esse jornal foi extinto etc. e tal. Mas aí eu era uma espécie de repórter amador. Por conta disso, eu vivi todos os problemas ligados à administração fazendo o curso, e, também, como uma espécie de estagiário do Semanário na Fundação. Ainda por conta disso eu tive incursões na UNE, União Nacional dos Estudantes, que não foi na época do Clemente 6 . O Clemente é mais novo do que eu. Ele chegou depois. Na UNE, uma época lá, eu estava respondendo, acho que como secretário geral, e convidei o governador do Piauí para ir lá fazer uma palestra. Não disse a ele que era do Piauí. Presidi a reunião, muito debate, muita crítica... O nosso governador era de uma linha de esquerda forte, tanto é que foi cassado muito rapidamente. No meio da coisa ele disse: "vem cá, você é do Piauí?" Eu digo: "sou”. Quase que eu dizia: "sou do Piauí, e daí?" Então ele disse: "olha, quando você terminar o curso me passe um telegrama. Eu te mando uma passagem, e você vai então a Teresina conversar comigo. Eu assumo no dia $1^{\circ}$ de janeiro". Por conta dessa conferência que eu convidei o governador para ir fazer, abriu assim... Aí eu cheguei à Sudene [também] por conta disso. Então, eu fui conversar com o Chagas Rodrigues 7 , que já faleceu, e lá eu virei tudo, [até] dono da Rádio Clube de Teresina, que atualmente é quem retransmite a Globo, e estive lá em alguns cargos. Na verdade, tem coisas na vida gente... Eu fui funcionário da Rede Ferroviária Federal durante 9 o dias, porque eu passei no concurso, assumi, mas aí o governador [do Piauí] me chamou. Eu conversei com ele e ele me convidou logo para ir lá: queria estruturar a Secretaria de Planejamento. A Sudene começava essa onda. Acabava de ser criada, estava quentinha. E a

6 Clemente Rosas, técnico da Sudene (1963-1964 e 1985-2001).

7 Francisco das Chagas Caldas Rodrigues (1922 - 2009) Governador do Piauí (19591962), Deputado Federal pelo Piauí (1951-1959; 1963-1969); Senador pelo Piauí (1987 -1995). 
gente, para vocês terem uma ideia - é interessante, também, como lição na vida - tem que fazer opções, às vezes arriscadas, mas tem que fazer. Na Rede Ferroviária eu ganhava o triplo do que o Estado iria me pagar como secretário. O governador disse: "eu vou tentar a tua disposição com o Renato Feio", que era o presidente da Rede na época. Mesmo ele sendo ligado ao João Goulart, ligadíssimo, presidente que eu conheci também pessoalmente, ele não conseguiu que eu ficasse à disposição. E eu cheguei no Palácio, e o governador disse: "está aqui a negativa contra a sua disposição." Eu: "governador, não tem problema, eu vou pedir demissão". "Você vai pedir demissão?" "Vou. Governador, eu sou muito novo para estar preocupado com a aposentadoria”, foi a minha resposta para ele. Pedi demissão da Rede. Agora, não fiz à toa. Foi dentro de uma concepção de planejamento global e de longo prazo. Eu digo: "na Rede Ferroviária eu vou ficar o tempo todo fazendo cálculo de custo de transporte ferroviário. E vou me aposentar aí. Aqui não. Em terra de cego quem tem um olho é rei. Eu vou criar a Secretaria de Planejamento, vou participar da reunião da Sudene, quer dizer, vou estar em reuniões com o BNDE atrás de financiamento, Banco do Nordeste... É outro mundo".

\section{- O senhor tinha quantos anos?}

Tinha 23 anos e meio, eu me formei com 23 anos.

- Então eu posso dizer, talvez, que o senhor foi o conselheiro mais jovem a participar das reuniões do Conselho Deliberativo da Sudene - Condel?

Eu acho que sim. Eu convivi com gente importantíssima: o general Afonso de Albuquerque, da ala esquerda do Exército; um grande amigo dele que também acabou sendo superintendente da Sudene, que foi o general Euler Bentes Monteiro, um dos melhores superintendentes que a Sudene teve... Ao lado de Celso Furtado, eu reputo os dois melhores superintendentes da Sudene: o general Euler e o general Nilton, este último sem comparação. De forma que eu cheguei na casa assim, no meio daquele bando de gente sabida... Tudo governador e eu ali ouvindo. O Chagas Rodrigues vinha muito pouco à instituição.

\section{-Chagas Rodrigues era quem na Sudene?}

Ele era conselheiro, governador do estado do Piauí. 


\section{- Então o senhor vinha representando ele?}

É, eu vinha representando o Francisco das Chagas Caldas Rodrigues, governador do Piauí. E o secretário executivo do Conselho era o Osmário Lacet. Eu tive muito com ele. Eu não tenho segurança, mas eu acho que foi na segunda reunião do Conselho. Eu estou em dúvida agora se foi na reunião do Conselho ou na reunião do Codeno, que o doutor Celso esteve lá, e lá eu conheci o Osmário, dei apoio, etc. e tal. Foi por aí. Agora, voltando à Sudene e as lições do ministro Celso Furtado. Como ele começou a operar? Chegou aí não havia nenhum entendimento de desenvolvimento. A maioria dos profissionais da região e até do Brasil não tratava o problema do desenvolvimento dentro de um enfoque global; só dentro do viés da economia. Então o doutor Celso partiu para alguns princípios básicos. Celso era um padrão extremamente austero. Ele falava com as pessoas de cima para baixo, guardava uma certa distância. É um depoimento pessoal. No $\mathrm{JK}^{8}$, por exemplo, quando ele entrava no elevador, se tinha quatro pessoas, o elevador subia direto para o $13^{\circ}$ andar e só depois voltava distribuindo o pessoal. São coisas que não estão escritas. Então, isso não significava pernosticismo, orgulho. Era o estilo do cara. Até que a gente aceitava isso com muita tranquilidade. Mas, evidentemente, que ele começou: "eu tenho que conhecer o Nordeste". Foi a estratégia. "Então para eu conhecer o Nordeste, eu tenho que fotografar o Nordeste". Aí passamos a ter o brutal programa de levantamento aéreo fotogramétrico feito na época por uma empresa que não existe mais chamada Cruzeiro do Sul. Então, o grande trabalho inicial foi hidrológico, geológico, cartográfico, para a gente ter mapas e cartas que pudessem planejar e intervir sobre a realidade. Dentro disso a segunda linha foi: "tem que ter gente para fazer as coisas". Foi outra grande lição. Ele vinha da Cepal e aí se articulou com ela. A Sudene montou um programa de formação chamado de TDE (Técnicos em Desenvolvimento Econômico). Qual era o objetivo da Cepal aqui no início? Qual era o objetivo disso? Celso queria que o advogado, que o economista, que o agrônomo, que o engenheiro, quando tratasse o problema do desenvolvimento tratasse dentro de um enfoque global. O enfoque dele era criar um engenheiro do desenvolvimento e não um fazedor de estrada, às vezes sem nenhuma preocupação com o escoamento adequado [da

8 Edifício JK, segunda sede da Sudene, na Av. Dantas Barreto, 315, Santo Antônio, Recife-PE. 
produção]. Então, tinha o engenheiro do desenvolvimento, o economista do desenvolvimento, o advogado do desenvolvimento, e não advogado com mentalidade de promotor, que ele não admitia. Ele dizia: "gente, advogado é para resolver problema, não é para me dizer o que eu não posso fazer! Vocês têm que ser profissionais de fazer as coisas". Então, eu sou produto desse curso. O Salmito', que foi superintendente, fez o curso; o doutor Clemente Rosas foi meu colega de turma no curso... Então, faz levantamento aéreo fotogramétrico, treina pessoal e dá bolsa de estudo para as universidades que interessam à Sudene. A Sudene passou a dar bolsa de estudo para todos os alunos de Economia, de Agronomia, de Geologia, que eram as áreas consideradas mais prioritárias de curto prazo. Ele foi muito criticado no início por não ter dado prioridade à Educação. Não é verdade. Ele dizia o seguinte: "em um primeiro momento eu preciso ter quem planeje a Educação. Como se faz educação? Qual é o diagnóstico da educação?" Então ele montou, também, vários cursos de planejamento e programação educacional. Veio gente do mundo todo aí. Eu lembro, assim, de uns dez cursos de planejamento ao lado do de desenvolvimento. Agora, na estratégia montada, o outro segmento que ele adotou foi criar o mínimo de infraestrutura que pudesse trazer empresários. Por exemplo, nós não vimos um hotel de quatro estrelas no Nordeste em 1960, nenhum. Então Celso procurou construir estradas básicas, garantir o mínimo de aparelhamento dos portos para poder dar vazão à produção... quer dizer, ele procurou fazer o possível para que o Nordeste tivesse condições mínimas de infraestrutura, para iniciar um processo sustentável de desenvolvimento.

- Doutor Leonides, o senhor acha que o projeto da Sudene era um projeto avançado demais para a sociedade da época, ou não?

Era extremamente avançado. Por que avançado? E por que continua avançado? Não existe no Brasil e, se duvidar, no mundo, uma

9 Valfrido Salmito, nono superintendente da Sudene (1978 - 1984). 
instituição como foi a Sudene! Principalmente na sua concepção. Na hora que você coloca governadores, ministros da área econômica, Banco do Brasil, Banco do Nordeste... você junta tudo num bolo só - o processo decisório nacional e regional - e você obriga esse Conselho a desenvolver um raciocínio de desenvolvimento?! ... E Celso fazia isso com uma maestria impressionante! Cada reunião que a gente tinha com ele era uma aprendizagem de laboratório!

\section{- O senhor disse que a Sudene foi um projeto muito avan-} çado para a época. É possível imaginar a Sudene sem o Celso Furtado?

Quanto a concepção da instituição, eu gostaria de fazer o seguinte comentário: a Sudene, sob o ponto de vista jurídico, é um ente único, composto por um Conselho e por uma Secretaria Executiva. Eles não existem separadamente, como se tentou fazer recentemente. Um dos principais avanços da instituição, quando ela teve um Conselho basicamente político e uma Secretaria Executiva, serviu para nos dizer: "olha, não adianta fazer determinadas proposições porque não vai haver suporte político". Isso não significava limitar nossa capacidade técnica de realizar diagnósticos, prognósticos, objetivos e metas. Mas alertava para o seguinte: a gente podia fazer, podia propor avanços, mas sabendo que teria que desenvolver uma estratégia especial para isso. Por outro lado, dentro da mesma instituição, os políticos sabiam que era um grande problema inicial que a gente tinha com eles: faziam determinadas proposições que não tinham nenhuma sustentação em termos de desenvolvimento. Então, nós delimitávamos, dávamos referencial para os políticos de um modo geral, e eles também nos davam. Esse processo interativo foi altamente benéfico. Por outro lado, tinha algo extremamente complicado de administrar e que exigia uma grande capacidade de negociação e articulação: a Sudene tem uma dupla vinculação. Ela é subordinada ao Poder Executivo, mas não é integralmente subordinada, porque era subordinada, também, ao Conselho, que é composto por governadores eleitos por voto direto. Então, o superintendente tem que fazer, o tempo todo, uma articulação entre a área política do Conselho e a área política de todos os estados, partindo do pressuposto de que os estados são personalidades jurídicas e de direito público autônomos, não subordinados à Sudene. Compõe o Conselho, mas a Sudene não tinha poder de mando. Nós 
ganhávamos muito espaço quanto a um possível poder de mando pela competência técnica; nós tínhamos muito mais condição técnica de orientar os estados. Hoje, não. Os estados têm muito PHD's, tem muito mestre, belas universidades, grandes centros de pesquisas. Então, a postura de uma instituição desse tipo tem que ser diferente. A estratégia inicial da Sudene foi muito produto da filosofia e da ação da Cepal. Celso veio de lá com toda essa filosofia, discernimento, competência, inteligência, capacidade de negociação, capacidade de articulação... Ele transformou o que era, predominantemente, planificação estatal em uma ação planificadora global, considerando a integração entre o setor público e o setor privado. E teve um grande mérito: ele incutiu em cada um de nós, com muita veemência, com muita competência, a postura de desenvolvimentistas. Tanto é que em um dos livros dele ele botou bem no início assim: "aos companheiros da Sudene, peregrinos da ordem do desenvolvimento." Lindo isso, não é? Ele era o grande líder de todos nós e nos chamava de peregrinos, de forma que eu acho que, sem ele, poderia ter havido uma Sudene, mas não uma Sudene de desenvolvimento como ela foi durante muito tempo. Dentro dessa conotação do modernismo dela, como decorrência dessa articulação, nós tivemos outro aspecto que normalmente a área acadêmica, por exemplo, não menciona e alguns até resistem a admitir. Como se trata de um depoimento, para não gerar dúvida de pesquisa, eu vou abordar o assunto. A Sudene foi a primeira experiência de planejamento sistematizado do Brasil. Quando eu dizia isso em minhas conferências, inicialmente havia um choque. Veja, a Sudene é de 1959, o cargo de ministro de Planejamento no Brasil é de 1962. Então, o planejamento nacional institucionalizado veio depois da Sudene. E o que nós profissionais chamamos planejamento? Veja, eu como professor, de vez em quando, fazia a seguinte pergunta: "planejar é elaborar plano?" Inicialmente, 90\% dos alunos respondiam que sim. Não é não! Planejar não é elaborar plano. Planejar é você iniciar um processo com estudos, pesquisas, diagnósticos, prognósticos, estabelecimento de objetivos, fixação de metas, estimativa de recursos, definição de estratégias, montagens de esquemas operacionais, acompanhamento, controle e avaliação, retorno dentro do processo, não para o processo. Aí, alguém nas conferências dizia: "mas professor, e o plano SALTE, do presidente Dutra, saúde, alimentação, transporte, energia, foi de 1958; e 
o Plano de Metas do Juscelino, não são exemplos de planejamento?" Dentro do conceito de planejamento, não é. Foi algo transitório, que teve como produto o Plano de Metas. Aí acabou, desapareceu, porque não era objetivo continuar o processo. Nós tivemos, sim, algumas experiências dentro do conceito de planejamento estadual. Por exemplo, a Codepe ${ }^{10}$, em Pernambuco, é anterior à Sudene e, na Bahia, também houve uma Comissão

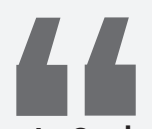

A Sudene foi a primeira experiência de planejamento sistematizado do Brasil. Quando eu dizia isso em conferência, inicialmente, havia um choque. Veja, a Sudene é de 1959.0 cargo de ministro de Planejamento no Brasil é de 1962. Então, o planejamento nacional institucionalizado veio depois da Sudene. de Planejamento Econômico, criada em 1955, também antes da Sudene, mas foram experiências localizadas. Nós tivemos a sorte aqui de ter Celso Furtado, que foi nomeado Ministro Extraordinário de Planejamento em 1962. A Sudene, que já era forte, subordinada diretamente à Presidência da República, passou a ter, além do seu superintendente, o ministro de Planejamento do país. Foi quando o meu estimado amigo Chico Oliveira ${ }^{11}$, com quem eu convivi bastante, assumiu a Sudene na prática. O Celso vinha pouco aqui. O Ministério do Planejamento era no Ministério da Fazenda, lá no Rio de Janeiro, na avenida Antônio Sales, mais ou menos no centro da cidade. De forma que a gente, pela pujança da Sudene, tinha relacionamento direto com o ministro do Planejamento. Os nossos planos diretores, que eram elaborados pela instituição e negociados no Congresso, tinham um trânsito absoluto. Por quê? Porque o Ministro aprovava. Estava elaborando com a gente mesmo, e ficava tudo mais fácil.

10 Criado em 1952, a Comissão de Desenvolvimento Econômico de Pernambuco CODEPE, órgão consultivo do Governo Estadual e de assistência às iniciativas de desenvolvimento econômico e modernização do Estado, que deu origem ao Conselho de Desenvolvimento de Pernambuco - Condepe, que juntamente com a Fundação de Desenvolvimento da Região Metropolitana do Recife - Fidem e a Fundação Instituto de Administração Municipal - Fiam, foram incorporados e formam hoje a Agência Condepe/Fidem. http://www.condepefidem.pe.gov.br/web/condepe-fidem/exibir_ noticia?groupId $=19941 \&$ articleId $=35475356 \&$ templateld $=18792964$

11 Superintendente-Adjunto da Sudene (1959-1964), vide entrevista nesta coletânea às páginas 74-108 
- Como é que o senhor avalia o impacto do golpe militar de 1964 na Sudene e no projeto de desenvolvimento do Nordeste?

Na Sudene, o impacto inicial, evidentemente, foi muito complicado e desastroso. Nos três dias subsequentes ao golpe eu estive com o doutor Celso Furtado no apartamento dele ali em Boa Viagem, perto do Pina, num prédio bem baixinho. Estive lá com ele algumas vezes e com José Maria Aragão. Quer dizer, ele teve personalidade para ficar. Enfrentou o auge da confusão e, seis dias depois, foi à Sudene, seis horas da tarde, e passou a instituição para o general da Reserva, Expedito Sampaio. Bom, o impacto. Nós tínhamos uma brutal equipe técnica. Ele saiu pela porta da frente, respeitado pela área militar, tomou o avião e foi-se embora para o Chile, sem ser corrido e perseguido, nesse momento. Depois, ele foi cassado, por outros motivos, inclusive. Então, o grande impacto: a desarticulação completa da instituição. Muita gente desapareceu logo por conta, antes de ser, digamos, identificada. Muita gente foi presa e, evidentemente, houve uma desarticulação completa na instituição. Se você perguntar: "e professor, o senhor estava lá?” Eu estava lá, eu vi as coisas. Um depoimento interessante, que normalmente eu acho que ninguém acha em livros: no dia da revolução, dia 31 de março de 1964, eu estava no corredor e vi aquele pânico. Não sei o que lá, tanque 'assim' na rua, e eu ia para o Gabinete dele (Celso), para tentar saber de alguma coisa. Ele saiu do Gabinete e foi ao corredor. Tinha um colega nosso, que era o tesoureiro, Robério. Muita gente ainda o conhece por lá. Celso chegou perguntando: "cadê o Robério?" Gente, parece que eu estou vendo! E deu uma ordem: "Robério pague a todo mundo"! Naquele tempo não tinha esse negócio de banco, não. Era tudo na tesouraria. A gente ia receber em dinheiro. Celso disse: "Pague todo mundo, porque a gente não sabe o que vai acontecer. Vamos resguardar os nossos funcionários". E ainda recomendou: "gente, receba o dinheiro e vá para casa. E evite aglomerações”. Muito bem, isso eu vi. Aí os colegas começaram a desaparecer todos.

\section{- Que horas mais ou menos foi isso?}

De manhã, foi quando ele saiu do Gabinete e mandou pagar todo mundo. Depois, ele saiu da Sudene e foi para o Gabinete do Arraes. Eu digo isso porque eu morava no Lido Hotel. É bom saber problemas da história, não é? Eu morava no Lido Hotel, que era ali na Riachuelo, e estava na porta vendo a confusão. Não sabia o que era aquilo direito. 
Quando menos espero, uma e meia da tarde, o Arraes já tinha sido preso. O Celso passou na frente e ainda me bateu a mão. Passou ele, e eu acho que estava com o Chico Oliveira. Não tenho certeza... Essa desarticulação institucional gerou pânico e a Sudene virou, durante uma época, terra de ninguém. Chegava alguém: "você está preso", e levava. A gente procurava, mas a pessoa já não estava mais na sala. Os jovens não viveram isso, mas a gente que viveu... Eu era chefe da Divisão de Assistência Financeira Internacional. E o pior: haveria uma reunião do FMI no Rio, dez dias depois [do golpe] e a Sudene estava designada para participar. Aí eu estou lá embaixo e a Clélia Reis, que era a secretária, recebe uma ligação da Maria Inês... Parece que era a secretária do Celso. Aí ela diz: "olha, estou aqui com a convocação, não sei o que lá, manda o diretor aqui". Eu digo: "olha Maria Inês, não tem diretor aqui não, sumiu tudo". "Mande fulano". "Não tem ninguém Maria Inês". Aí esse general que eu não conhecia pegou o telefone e disse: "o que o senhor é aí?" Eu digo: "sou técnico aqui, chefe da Divisão..." "Suba”. Lá no JK. Subi. Ele: “o que é isso aí?" "General, reunião do Fundo Internacional...” "Você está a par disso?” Digo: “estou em termos, mas quem estava designado para ir representar a Sudene era o doutor José Macedo Lins", que era o diretor. Desapareceu espontaneamente. O vice era José Rômulo Rodrigues, que tinha desaparecido também. E ele disse: "então o senhor vai para a reunião". "Eu?" Eu não era nada, eu era um chefete. Disse: "não, o senhor assume lá". A primeira vez que eu assumi alguma coisa lá na Sudene foi designado, de fato, por esse general. Era um cara cotado, assim, decente. Então, aliás sobre isso vale a pena um comentário por dever histórico de justiça. A Sudene teve muita sorte com os generais que estiveram por lá. Muita sorte mesmo, porque os militares, ao lado de tudo aquilo terrível para o país, eles são formados para defender a pátria. Eles admitem, evidentemente, que tudo aquilo faz parte de uma defesa nacional. Então, o general Euler Bentes, o general Tácito de Oliveira, o general Evandro Moreira de Souza e Lima, olha, sustentaram posições e foram fundamentais para que não acontecesse coisa pior lá na Sudene. Eu me lembro do general Euler, que era general de divisão e depois virou general de Exército, tinha autoridade junto ao general Justino Alves ${ }^{12}$. Eu vi várias vezes ele proibir que se prendesse qualquer pessoa dentro

12 General Justino Alves, na época dos acontecimentos narrados pelo entrevistado, tinha sido nomeado comandante do $4^{\underline{0}}$ Exército, sediado em Pernambuco, em 
da Sudene. Proibiu, telefonou para o general. E eu vi, sabe por quê? Eu sou testemunha ocular da história. Eles prenderam um funcionário meu. Chegou o capitão para prender alguém e o menino era assim meio metido a besta, aí eu disse: "não, o senhor não vai prender não, o senhor só prende se for com ordem do superintendente". "Nós temos autoridade, eu levo o senhor também". Eu disse: "bom, a força você leva". Mas aí eu peguei o telefone, pedi permissão a ele e falei: "general Euler, está sendo preso aqui fulano, fulano, e fulano". Aí ele disse: "mande esse oficial subir aqui". O oficial subiu e ele enquadrou o cara. Telefonou para o Justino Alves e disse assim (essa eu ouvi também, porque eu era muito ligado): "general, na casa que eu dirijo quem manda sou eu". Era um general falando para outro general. "O senhor vai prender quem o senhor quiser quando o funcionário sair na porta, quando terminar o expediente, às seis horas, que ele sair para casa. Aí o senhor prende. Eu não tenho nada com isso. Mas dentro da instituição só acontecem as coisas eu autorizando". Bom, como a instituição resistiu a isso? E ela não soçobrou de vez, mas houve uma desarticulação brutal. O doutor Celso criou uma filosofia de desenvolvimento em todos nós. O dirigente saiu, mas quem ficou conseguiu segurar o barco. O Clemente Rosas desapareceu. Tinha sido da UNE e, de certa forma, pagou o pato, coitado. Depois, foi reintegrado na forma da Lei e se aposentou como procurador da Sudene, um excelente profissional! Todo pessoal da assessoria técnica, recursos humanos, o pessoal de recursos naturais, cada um nas suas áreas, quando era convocado para uma discussão, para uma reunião, que havia muitas e continuou havendo, mantinha a filosofia do doutor Celso Furtado, que nós havíamos aprendido e ele havia incutido na cabeça de todos nós, de que aquilo é que era o desenvolvimento.

- E o senhor que ficou na Sudene não viu assim que houve um silêncio depois que ele foi embora? Porque a gente não encontra nada nos jornais, os jornais não registraram nada... Sim.

\section{- Tem um silêncio.}

Você diz em termo de poderia ter havido uma reação?

substituição ao general Humberto Castelo Branco, que na ocasião havia sido transferido para assumir a chefia do Estado-Maior do Exército, no Rio de Janeiro 


\section{- Sim.}

Não, não houve reação porque a filosofia era de sufoco da área militar. Não havia nenhuma capacidade organizada... nenhuma reação. Os jornais eram todos censurados. Quem faz uma pesquisa nos jornais da época não pode concluir que nós estávamos de acordo, [já] que éramos chamados de "as viúvas de Celso Furtado".

\section{- Ah, eles diziam isso?}

Diziam com a gente. Porque quando a gente abordava o assunto e lamentava, em pequenos grupos e grupos maiores, a gente era apelidado de 'viúvas do Celso Furtado'. Você está entendendo agora, não é? Nós não podíamos fazer nada, ninguém podia fazer nada no país, num determinado momento. De forma que, agora, ele foi, mas as ideias, o comportamento, a postura, a estratégia, ficaram com a gente. $\mathrm{E}$ a gente continuou fazendo.

\section{- Doutor Leonides como era a relação da Sudene com o mundo} exterior, com outros países, com as pessoas estrangeiras, era muito forte?

Extremamente forte, principalmente no primeiro momento, o do doutor Celso... E logo em seguida, também, dentro da estruturação que ele mesmo tinha feito, a gente fez um convênio com a França, e estudamos todo o Vale do Jaguaribe, no Ceará, antes da construção de Orós. ${ }^{13}$ Estudamos tudo. Fizemos um enorme convênio com a Organização das Nações Unidas para Alimentação e Agricultura FAO e toda essa onda de Petrolina surgiu com a Sudene. A gente criou projetos pilotos, um em Mandacaru, o outro não me ocorre exatamente... um de cada lado do rio.

\section{- Bebedouro}

Bebedouro, obrigado, o outro projeto é Bebedouro. Começou com a FAO por meio de convênio ${ }^{14}$. Eu conduzia essas coisas. Com o

13 O entrevistado se refere ao Açude de Orós, que teve sua construção interrompida em 1922 e retomada em 1958. Dois anos depois ainda em obras, no dia 26 de março, o reservatório com 700 milhões de $\mathrm{m}^{3}$ mais a vazão do rio Jaguaribe, rompeu causando a catástrofe de Orós. Por determinação do presidente Juscelino Kubitscheck, o obra foi retomada e inaugurada em 11 de janeiro de 1961.

14 O artigo A transformação do Vale do São Francisco nos anos 196o de Sérgio Marques Cavalcanti Filho, permite uma visão das mudanças no Semiárido http://procondel. 
governo da Alemanha nós fizemos convênios nas áreas de geologia, hidrologia e cartografia. Chegou uma época aqui que a gente tinha 80 alemães, medindo queda d'água, fluxo d'água, para ver como é que ia se comportar no caso de seca, vazão, tudo isso. Com o governo de Israel a gente pegou uma missão para fazer um estudo no sul do Piauí, sudoeste do Piauí, sobre hipóteses de irrigação. Quando o presidente Kennedy lançou 'Aliança para o Progresso' em 1961, o presidente Juscelino Kubitschek já havia lançado a Operação Pan-americana em $1958^{15}$, dentro de uma filosofia de articulação da América Latina. Com essa proposta, Juscelino enviou uma carta ao então presidente dos Estados Unidos, Dwight Eisenhower (1953 - 1961). No bojo da Aliança para o Progresso nós realizamos aqui, em todos os estados, uma programação intensa nas áreas de educação (que era prioridade), agroindústria, agricultura etc. A Sudene foi designada pela presidência da República como agência responsável pela execução do programa da Aliança para o Progresso no Nordeste. Eu tive relação direta com esse projeto, mas inicialmente foi o diplomata Samuel Pereira Guimarães. Eu era o adjunto dele, mas ele depois foi embora, negócio de carreira do Itamarati e tal. A Sudene, na época, não trouxe outro diplomata e me designou para continuar. A Lei não exigia que fosse um diplomata, aí eu fiquei lá. Ou seja, havia um grande relacionamento na área, tanto no que a gente chama tecnicamente de assistência técnica estrangeira bilateral, de país a país, como a assistência técnica multilateral com as Nações Unidas, via UNESCO.

- Eu queria encaminhar para uma última pergunta que é assim: como é que o senhor avalia o papel da Sudene hoje? E que Sudene seria possível no contexto atual?

Nós temos que ter cuidado para responder uma pergunta como essa, porque, antes disso, nós precisamos partir de alguns pressupostos. Primeiro, um país com essa dimensão tem uma grande diversificação. O crescimento do país e do próprio Nordeste faz com que os

sudene.gov.br/ArtigosDetalhes.aspx?Id=1033.

15 "A Operação Pan-Americana - OPA é uma das iniciativas da diplomacia brasileira que podem ser consideradas fundamentais para a compreensão das inflexões da ação internacional do Brasil e do processo de amadurecimento e ampliação dos horizontes da sua visão de mundo." In Há cinquenta anos a Operação Pan-americana, Lessa, Antônio Carlos. https://www.scielo.br/scielo. php?script=sci_arttext\&pid=So034-73292008000200001 
governadores estejam mais preparados para enfrentar um conjunto de problemas. Então, nós precisamos de uma instituição regional de desenvolvimento para tratar dos assuntos sub-regionais do Nordeste, ou de qualquer macrorregião. Por exemplo, a transposição das águas do São Francisco. Um dos grandes erros do governo é está dando um tratamento setorial a um problema que é global e espacial. Esse programa tinha que ser de uma agência regional, ou seja, é um programa sub-regional. A Transnordestina, outro exemplo, tratado setorialmente pelo Ministério dos Transportes. Pior do que tudo isso é a falta de um programa espacial, global, para o Semiárido, que corresponde a $51 \%$ da região Nordeste. Ou seja, uma série de distorções... E tem mais: a instituição de que se está precisando é uma instituição que tenha, não mais grandes economistas, grandes articuladores políticos. Os estados e as universidades estão cheios de técnicos competentes. O que nós temos é que ter uma instituição que tenha competência para articular esse povo, no sentido de induzi-los em um único sentido.

\section{- O senhor enxerga isso possível hoje?}

Acho possível. É lento, mas é possível. Tanto é que eu ainda estava lá e defendi a tese, e não tive muito êxito, de nós passarmos a formar negociadores. Nós não temos negociadores, nós não temos articuladores. Quando eu digo não temos, não é bem assim. Todo político, em princípio, é um negociador. Mas falo de um negociador de outro tipo, de articulação de liderança. Como nós não temos uma instituição regional de desenvolvimento, as universidades fazem uma coisa, os governos fazem outras, os Ministérios fazem outras... Eu falo disso nas minhas conferências, mas aí o sujeito entra logo e diz: "é saudosismo, não tem sentido, as coisas mudaram..." Não é isso. $\mathrm{O}$ que eu falo é de uma instituição regional de desenvolvimento, que pode ser a Sudene... Não sei. Mas que desenvolva algumas expansões no campo sub-regional e articule lideranças técnicas, nos diversos níveis da região. Eu gostaria de dizer, para encerrar, que quando outro grande economista, chamado de monetarista da direita, Roberto Campos ${ }^{16}$ assumiu o Ministério do Planejamento ele fez o que qualquer um

16 Roberto de Oliveira Campos (1917 - 2001), economista foi presidente do BNDES (1958 - 1959), Ministro do Planejamento (1964 -1967), Senador por Mato Grosso (1983 1990) Deputado Federal pelo Rio de Janeiro (1991 - 1999). 
teria que fazer. Eu, às vezes em conferência, sou criticado por dizer isso. $\mathrm{O}$ que foi que o Campos fez? Aquela mania que a gente tinha de ser único, tinha o ministro do Planejamento e tudo, desapareceu. Todos os grandes objetivos são nacionais, não são do Nordeste. Os objetivos e metas do Nordeste têm que apresentar uma desagregação dos objetivos e metas nacionais. Dentro desse enfoque, vamos dizer, Campos, na inflação desesperada, partiu para o equilíbrio orçamentário: eliminação de subsídios, controle salarial, economia de mercado. Isso significou o seguinte: nivelou o Nordeste para baixo, porque na época que ele fez isso o governo não deu prioridade a região. Nós passamos a ser tratados iguais a qualquer um. Os nossos planos regionais de desenvolvimento, que eram altamente prioritários, aprovados pelo Congresso, foram progressivamente esvaziados e nós passamos a ser um capítulo da história dos Planos Nacionais de Desenvolvimento. Daí porque no meu livro 'Sudene 50 Anos' eu evitei fazer a abordagem substantiva. Por exemplo: a educação passou de tanto para tanto, o produto cresceu de tanto para tanto, digamos, os anos de vida passaram de tanto para tanto. Isso aí todo mundo está dizendo. Eu concentrei esse livreto nos aspectos institucionais que eu abordei aqui mais ou menos, políticos e institucionais. A partir dessa centralização aconteceu o que todo mundo diz ainda hoje: esvaziamento da Sudene.

- A gente gostaria que o senhor pudesse resumir qual foi o papel da Sudene no desenvolvimento do Nordeste e quais são os desafios hoje.

A Sudene foi uma instituição que ordenou o processo e criou na região um tratamento de desenvolvimento para os problemas do Nordeste. Anteriormente, o único tratamento que tinha de enfoque de política era o aumento da oferta d'água, que era o grande papel do DNOCS, que ele cumpriu bem o seu papel. A Sudene teve a sua função de contribuir para gerar uma mentalidade, um tratamento, uma abordagem global, em termos de desenvolvimento, dos problemas da região. Essa foi a grande contribuição. Em todo o Nordeste você ainda encontra profissionais gerados pela Sudene e ex-funcionários da instituição em postos chaves da administração pública no Nordeste e no plano federal. O papel de uma instituição, e nós estamos carentes de uma instituição regional, é atuar nesses espaços sub-regionais, com programas da magnitude da Transnordestina, da transposição, 
na questão do algodão. O problema do algodão não é só da Paraíba; é da Paraíba, do Rio Grande do Norte, do Ceará, do Piauí. Não pode ser a abordagem de melhoria genética do algodão como tratamento puramente estadual. O governo precisa criar uma agência de desenvolvimento regional. Agora, para encerrar, uma afirmativa quase manchete jornalística: a Sudene não interessa ao governo federal. Choca. Por que não interessa? Porque se nós tivermos uma Sudene forte, com 11 governadores atualmente - os 9 do Nordeste geográfico mais Minas Gerais e Espírito Santo - você cria uma força política que, embora muitos sejam da base de governo, na hora de discutir alguns interesses entre as regiões eles vão se aglutinar e se estabelecer como um grupo político sobre o governo para assumir o processo decisório. Ora, a estratégia militar é dividir para se fortalecer. É muito mais fácil chamar o governo do Rio Grande do Norte sozinho: "olha, eu quero tanto", "eu vou te dar tanto", tudo o que o Celso tentou evitar e conseguiu. Todo o enfoque era dar um tratamento global e evitar o pires na mão, em nível do governo central. Agradeço a você Fernando, pela oportunidade, e a você, Angela, por esse esforço que você está fazendo, impressionante. Eu digo o seguinte: eu convivi com você no início desse processo. Tivemos várias reuniões. Você não sabe dimensionar a contribuição que está dando. Não é para nós do Nordeste, não. Você está dando [uma contribuição] em nível nacional, e um instrumento de pesquisa acadêmica para gerar efeito de demonstração, inclusive em outro estado. Agradeço aos companheiros ali, o Alan, os companheiros da técnica toda, e continuo a disposição. Muito obrigado. 